\title{
Gender-related response of lipid metabolism to dietary fatty acids in the hamster
}

\author{
Anne Morise ${ }^{1}$, Jacques Mourot ${ }^{2}$, Carole Boué ${ }^{3}$, Nicole Combe $^{3}$, Ghislaine Amsler ${ }^{1}$, Daniel Gripois ${ }^{1}$, \\ Annie Quignard-Boulangé ${ }^{4}$, Laurent Yvan-Charvet ${ }^{4}$, Evelyne Fénart ${ }^{5}$, Pierre Weill ${ }^{6}$ and \\ Dominique Hermier ${ }^{7} *$ \\ ${ }^{1}$ Laboratoire d'Endocrinologie de la Nutrition, Université Paris Sud, 91405 Orsay Cedex, France \\ ${ }^{2}$ INRA, SENAH, Saint-Gilles, 35590 L'Hermitage, France \\ ${ }^{3}$ ITERG-Nutrition, 35405 Talence, France \\ ${ }^{4}$ INSERM 465, 75005 Paris, France \\ ${ }^{5}$ ONIDOL, 75008 Paris, France \\ ${ }^{6}$ La Messayais, 35210 Combourtillé, France \\ ${ }^{7}$ UMR Physiologie de la Nutrition et du Comportement Alimentaire, INRA-INA-PG, 16 rue Claude Bernard, 75231 Paris Cedex 05, \\ France
}

(Received 21 June 2005 - Revised 21 November 2005 - Accepted 6 December 2005)

Gender and dietary fatty acids are involved in the regulation of lipid metabolism, disturbances of which can lead to pathologies such as metabolic syndrome or CVD. Possible interactions between these factors were investigated in male and female hamsters fed diets rich in either saturated fatty acids ('butter' diet) or in $\alpha$-linolenic acid ('linseed oil' diet). Gender effect predominated over the diet effect on cholesterol (CH) metabolism; compared to males, females exhibited lower concentrations of plasma total $\mathrm{CH}(-20 \%, P<0.001)$, LDL-CH $(-40 \%, P<0 \cdot 001)$ and HDL-CH $(-16 \%, P<0 \cdot 001)$, together with higher LDL receptor $(+40 \%)$ and lower HDL receptor $(-60 \%)$ hepatic content. Triacylglycerol (TG) metabolism was affected by diet above all: compared to animals fed the 'butter' diet, those fed the 'linseed oil' diet exhibited lower plasma $(-23 \%, P=0 \cdot 046)$ and liver TG ( $-20 \%$, $P=0.026)$ concentration which may result from both an increased $\beta$-oxidation $(P<0 \cdot 001)$, without any change in PPAR $\alpha$ mRA, and a decreased hepatic lipogenesis $(P=0 \cdot 023)$, without increased sterol response element binding protein $1 \mathrm{c}$ (SREBP1c) mRNA. The response to diet was much more pronounced in males than in females, without gender effect on the transcription level of PPAR $\alpha$ and SREBP1c. Finally, the 'linseed oil' diet decreased the insulin resistance index $(-80 \%, P<0.001)$ with a more marked effect in males, in relation to their higher hepatic PPAR $\gamma$ expression $(+90 \%, P=0.012)$. In conclusion, in our model, the response of either TG or CH to dietary fatty acids is modulated differently by gender. The possible relevance of these interactions to dietary practice should be taken into account in man.

$\alpha$-Linolenic acid: Gender: Lipid metabolism: Dietary fatty acids

Gender-associated responsiveness to diet has been involved in various pathologies linked to a disturbance of lipid homeostasis such as metabolic syndrome (Couillard et al. 1999), insulin resistance (Noonan \& Banks, 2000) or CVD (Cobb et al. 1993; Li et al. 2003). Lipid metabolism is clearly influenced by sex hormones. Compared to non-menopausal women, men have a more marked accumulation of fat in the intraabdominal depots, which results in disturbances of lipid homeostasis and contributes to insulin resistance (Couillard et al. 1999). Men exhibit also a more atherogenic lipoprotein profile with higher concentrations of plasma LDL-cholesterol (LDL-CH) and triacylglycerols (TG) and a lower concentration of HDL-CH (Carlson \& Ericsson, 1975; BonithonKopp et al. 1990; Couillard et al. 1999; van Beek et al.
1999). Before their menopause, women are therefore less susceptible to lipid-associated pathologies. For instance, the life-time risk of developing a CHD at age 40 years is $33 \%$ in women v. $50 \%$ in men (Lloyd-Jones et al. 1999). After menopause, their lipoprotein profile becomes similar to that of men (Bonithon-Kopp et al. 1990; van Beek et al. 1999). These modifications are probably due to the lack of oestrogen (Stampfer et al. 1991), and is attenuated by estrogenic treatment (Matthews et al. 1989).

Lipid homeostasis is not only modulated by sex hormones, but also by dietary fatty acids. The beneficial role of PUFA, and notably $n-3$ PUFA, has been largely described, especially through the regulation of genes controlling lipid metabolism (De Caterina \& Zampolli, 2001). Therefore, interactions of

\footnotetext{
Abbreviations: AA, arachidonic acid; ACC, acetyl CoA carboxylase; ACO, acyl CoA oxidase; ALA, $\alpha$-linolenic acid; CE, cholesteryl ester; CH, cholesterol; CPT, carnitine palmitoyl transferase; FAS, fatty acid synthase; FC, free cholesterol; G6PDH, glucose-6-phosphate dehydrogenase; HOMA, homeostasis model assessment; LA, linoleic acid; PL, phospholipid; SFA, saturated fatty acids; SR-B1, scavenger receptor class B type 1; SREBP, sterol response element binding protein; TC, total cholesterol; TG, triacylglycerol.

* Corresponding author: Dr Dominique Hermier, fax +331440872 46, email hermier@inapg.inra.fr
} 
dietary fatty acids with sex hormones in lipid metabolism are most likely, but remain poorly known. A meta-analysis of five human studies using high and low PUFA to saturated fatty acids (SFA) ratios concluded that normolipidaemic men and women show similar reduction in LDL-CH following dietary change from a high to a low SFA to PUFA ratio. By contrast, the response of HDL-CH was gender-specific, with females showing a greater fall in the potentially beneficial HDL-CH than males (Cobb et al. 1993). In response to dietary SFA and $\mathrm{CH}$ restriction, mildly hypercholesterolaemic men showed a more pronounced reduction in $\mathrm{CH}$ and plasma apoB than post-menopausal women ( $\mathrm{Li}$ et al. 2003).

The above studies were performed in human subjects, which did not enlighten about the mechanisms by which gender influences the response of lipid metabolism to dietary fatty acids. Relevant animal studies are few and focused, as in man, on the lipoprotein profile of the guinea pig (Fernandez, 2001) and the hamster (Wilson et al. 1999; Morise et al. 2004b). The present study was therefore designed to compare, in male and female rodents, the response of fatty acid and lipid metabolism to dietary fatty acids. The hamster has been chosen as a validated model for assessing the effect of dietary fat on lipid metabolism (Surette et al. 1992; Goulinet \& Chapman, 1993; Spady et al. 1999). The fatty acid profiles of the diets were radically different: the first one was rich in SFA (of which palmitic acid accounted for more than $50 \%$ ) and thus representative of atherogenic diets consumed in western countries. The second one was rich in $\alpha$-linolenic acid (ALA). Indeed, even if long-chain $n-3$ PUFA are best known to be protective against CVD (De Caterina \& Zampolli, 2001), some similarities in the precursor and its long-chain derivatives can be found in the literature as regards their effects on lipid risk factors of CVD as well as on CVD epidemiology. Indeed, in man, dietary ALA intake was associated with: (1) bioconversion into $20: 5 n-3$, which improves the balance of eicosanoids derived from 20:5 fatty acids (Pawlosky et al. 2001); (2) decreased triglyceridaemia in some patients exhibiting CVD risk factors (Wilkinson et al. 2005) or in an epidemiological survey (Djousse et al. 2003); and (3) protective effect on the relative risk from fatal CHD (Ascherio et al. 1996; Hu et al. 1997). Besides, in the male hamster, dietary ALA has been shown to reduce hepatic lipogenesis and triglyceridaemia (Morise et al. 2005). The aim of the study was to determine (1) whether the lipoprotein profile and the lipid risk factors of metabolic syndrome and CVD were influenced by fatty acids to the same extent in females as in males, and (2) which were the key enzymes and compartments of lipid metabolism, and the major transcription factors involved in the regulation of lipid metabolism by dietary fatty acids, that are involved in the gender-related differences.

\section{Experimental methods}

\section{Experimental procedure}

Animals. Twenty-six male and twenty-six female golden Syrian hamsters were obtained from Janvier (Centre d'élevage Janvier, Le Genest-St Isle, France) at 4 weeks of age. They were housed in colony cages with wood litter (four or five per cage $)$ in a controlled environment $\left(22^{\circ} \mathrm{C}, 14 \mathrm{~h}\right.$ light $-10 \mathrm{~h}$ dark cycle) and received ad libitum distilled water, and a ground commercial diet (UAR 113 containing, by weight,
$72.0 \%$ cereals, $17.8 \%$ soy meal, $6.0 \%$ fish meal, $4.2 \%$ vitamins and minerals mix, and providing $5.1 \%$ lipids and $19.3 \%$ proteins; UAR 113, Villemoisson, France). At 8 weeks of age, the hamsters were housed in colony cages with a wire floor, weighed weekly and fed experimental diets during 7 weeks.

Diets. The two experimental diets consisted (in weight) of $85 \%$ of the above commercial ground pellets, and either $12.5 \%$ butter and $2.5 \%$ sunflower oil in the 'butter' diet, or $12.9 \%$ linseed oil (Valorex, Javené, France), and $2.1 \%$ water and $0.031 \% \mathrm{CH}$ (5-cholesten-3B-ol; Sigma, St Louis, MO, USA) in the 'linseed oil' diet. The calculated composition (in weight) of the two diets was $16.4 \%$ protein, $52.9 \%$ carbohydrate, $17.8 \%$ lipid, $10.9 \%$ water and $4.6 \%$ minerals. Lipids provided about one-third $(36.5 \%)$ of total energy intake. The lipid and $\mathrm{CH}$ content of the diets and their fatty acid profile was determined as described later and are shown in Table 1. The experimental diets were formulated in order to differ mostly in their SFA and ALA content, while keeping oleic and linoleic acid (LA) proportion as close as possible.

Experimental design. Five days before the hamsters were killed, four per group were housed in individual cages with a wire floor in order to harvest their faeces. They received a single dose of two radiolabelled sterols $\left(\left[{ }^{14} \mathrm{C}\right] \mathrm{CH}\right.$ and $\left[{ }^{3} \mathrm{H}\right] \beta$-sitostanol) to measure their dietary $\mathrm{CH}$ absorption as described later. The others (nine in each group) were kept in colony cages. At 15 weeks of age, after 7 weeks on the experimental diets, all hamsters were fasted overnight, then weighed and anaesthetized by intramuscular injection of Zoletil 50 (Virbac, Carros, France) at a dose of $4 \mathrm{mg} / 100 \mathrm{~g}$ body weight. First, a limited blood sample (about $250 \mu \mathrm{l}$ ) was taken as fast as possible by intracardiac puncture, using a heparinized syringe (10 units heparin/ml blood), for determination of glucose and insulin concentrations, which are very sensitive to the stress induced by anaesthesia. Immediately

Table 1. Lipid, cholesterol and vitamin E content and fatty acid profile of the experimental diets

\begin{tabular}{|c|c|c|}
\hline & 'Butter' diet & 'Linseed oil' diet \\
\hline Lipid content (\% by wt of the diet) & $14 \cdot 6$ & $14 \cdot 8$ \\
\hline Cholesterol (\% by wt of the diet) & 0.068 & 0.067 \\
\hline Vitamin E (mg/kg) & $10 \cdot 2$ & $8 \cdot 6$ \\
\hline \multicolumn{3}{|l|}{ Fatty acid ( $\%$ of total fatty acids) } \\
\hline $10: 0$ & $1 \cdot 01$ & ND \\
\hline $12: 0$ & $2 \cdot 37$ & ND \\
\hline $14: 0$ & $8 \cdot 25$ & 0.14 \\
\hline $14: 1$ & 0.66 & ND \\
\hline $15: 0$ & 0.79 & ND \\
\hline $15: 1$ & 0.18 & ND \\
\hline $16: 0$ & $24 \cdot 31$ & $7 \cdot 68$ \\
\hline $16: 1$ & $1 \cdot 12$ & $0 \cdot 20$ \\
\hline $17: 0$ & 0.49 & $0 \cdot 10$ \\
\hline $18: 0$ & 7.92 & 3.82 \\
\hline $18: 1 n-9$ & $24 \cdot 60$ & $19 \cdot 00$ \\
\hline $18: 1 n-7$ & 0.49 & 0.49 \\
\hline $18: 2 n-6 t$ & 0.35 & ND \\
\hline $18: 2 n-6$ & $22 \cdot 72$ & $24 \cdot 11$ \\
\hline $18: 3 n-3$ & 1.91 & $43 \cdot 78$ \\
\hline $20: 0$ & 0.17 & 0.15 \\
\hline $20: 1 n-9$ & 0.55 & 0.26 \\
\hline $20: 5 n-3$ & 0.30 & 0.24 \\
\hline $22: 6 n-3$ & 0.25 & 0.23 \\
\hline$n-6: n-3$ & $9 \cdot 27$ & 0.55 \\
\hline
\end{tabular}

$\mathrm{ND}$, not detected. 
after, a larger blood sample was taken under the same conditions. Plasma was separated from blood by centrifugation for $20 \mathrm{~min}$ at $4^{\circ} \mathrm{C}$ and $1700 \mathrm{~g}$ then stored at $-20^{\circ} \mathrm{C}$. Erythrocytes were washed with saline, and stored at $-80^{\circ} \mathrm{C}$. After blood sampling, the abdominal cavity was opened surgically and bile was taken from the gall bladder and stored at $-20^{\circ} \mathrm{C}$. Liver was then carefully removed and weighed. Two samples of 1.0 and $0.3 \mathrm{~g}$ were immediately frozen in liquid $\mathrm{N}_{2}$ for the measurement of lipogenic enzyme activity and RNA extraction, respectively. Two other samples of 0.3 and $0.5 \mathrm{~g}$ were stored at $-20^{\circ} \mathrm{C}$ for further analysis of lipid composition and quantification of lipoprotein receptors, respectively. A $1 \mathrm{~g}$ sample was kept on ice for immediate isolation of microsomes, on the one hand, and mitochondria + peroxisomes, on the other hand (Souidi et al. 1999). Hamsters were then killed by section of the jugular vein. A red muscle (Vastus lateralis) was removed from the left leg and frozen immediately in liquid $\mathrm{N}_{2}$ for measurement of $\beta$-oxidation activity. Gonadal adipose tissue were removed and weighed. Lipids from plasma and liver were analysed in all hamsters (thirteen per group) in order to check whether the type of housing could modify lipid metabolism. In this respect, hamsters kept in collective cages (nine per group) did not differ significantly from those placed in individual cages for $5 \mathrm{~d}$ in order to measure $\mathrm{CH}$ absorption (four per group). However, results in the text and the corresponding tables and figures are from the nine hamsters kept in collective housing. All other biochemical measurements were performed in hamsters kept in collective cages throughout $(n 9)$ ). The present work was carried out in agreement with the French legislation on animal experimentation and with the authorization of the French Ministry of Agriculture (Animal Health and Protection Directorate).

\section{Analyses}

Lipid components and fatty acid profile. Diet: lipids were extracted according to Folch's method (Folch et al. 1957), dried under $\mathrm{N}_{2}$ and weighed for the calculation of total lipid content. They were then trans-methylated with $\mathrm{BF}_{3}$ in methanol $(14 \%)$ according to the method of Morisson \& Smith (1964). Fatty acid methyl esters were analysed by GLC (Fisons 8000; Thermo Products, Les Ulis, France) as described previously (Morise et al. 2004a). Neutral sterols (containing $\mathrm{CH})$ were extracted with petroleum ether after hydrolysis in basic conditions and $\mathrm{CH}$ was separated and quantified by GLC as described by Boehler et al. (1999). Vitamin E content in the diets was determined as described by the international standard organization (ISO9936:1997).

Erythrocytes: $1.5 \mathrm{ml}$ erythrocytes were treated according to the method of Folch et al. (1957). Total lipids were separated by TLC on $0.3 \mathrm{~mm}$ thick silica-gel (Kieselgel H 60; Merck, Darmstat, Germany) laboratory-coated plates using the solvent mixture hexane-diethyl ether-acetic acid ( $90: 10: 1$, by vol.). Fatty acid methyl esters from phospholipids (PL) were prepared by trans-methylation of individually isolated fractions in the presence of silica-gel and in the same conditions as described by Morise et al. (2004a). Fatty acid methyl esters were analysed according to Boué et al. (2000).

Dietary cholesterol absorption. Dietary $\mathrm{CH}$ absorption was measured in four hamsters per group, according to the method of radioactive faecal balance (Quintao et al. 1971) adapted to the hamster. This method is based on the ingestion of a single dose of two radiolabelled sterols $\left(2 \mu \mathrm{Ci}\left[{ }^{14} \mathrm{C}\right] \mathrm{CH}\right.$ (Perkin Elmer Life Sciences, Boston, MA, USA) and $1 \mu \mathrm{Ci}\left[{ }^{3} \mathrm{H}\right] \beta$-sitostanol (American Radiolabeled Chemicals, St Louis, MO, USA)) incorporated into the diet. Since $\beta$-sitostanol is considered not to be absorbed significantly, it was used as internal standard for $\mathrm{CH}$ absorption calculation according to the formulae:

$$
\text { Dietary } \mathrm{CH} \text { absorption }=1-\left(\left({ }^{3} \mathrm{H} /{ }^{14} \mathrm{C}\right)_{\text {diet }} /\left({ }^{3} \mathrm{H} /{ }^{14} \mathrm{C}\right)_{\text {faeces }}\right) \text {. }
$$

The ${ }^{3} \mathrm{H} /{ }^{14} \mathrm{C}$ ratio in faeces was determined after extraction of neutral sterol as described for dietary CH (Boehler et al. 1999).

Biochemical analyses. Plasma composition: glycaemia was determined colorimetrically using an enzymatic kit (Biochem, Aix-en-provence, France; Trinder, 1969) and insulinaemia using a RIA kit (sensitive rat insulin RIA; Linco, St Charles, MO, USA) and validated in the hamster in our laboratory. The insulin resistance index was calculated by the homeostasis model assessment (HOMA; Matthews et al. 1985).

TG, total cholesterol (TC) and PL were determined in plasma by colorimetric enzymatic methods (Richmond, 1973; Takayama et al. 1977; Fossati \& Prencipe, 1982; respectively), using the kits provided by Bio-Merieux (Marcy-l'Etoile, France). Analyses were performed with an automatic analyser (Abbott-VP, Rungis, France). Free cholesterol (FC) was determined manually using a procedure adapted from Richmond (1973). The concentration of cholesteryl esters (CE) was calculated with the formulae: $\mathrm{CE}=\mathrm{TC}-\mathrm{FC}$.

Plasma vitamin E concentration was measured according to the method of Menke et al. (2000). Briefly, after addition of 2,6-di-tert-butyl-p-cresol, vitamin $\mathrm{E}$ was extracted with hexane and separated by HPLC. Quantification was realized by adding $\alpha$-tocopherol as internal standard. Plasma malondialdehyde concentration was measured according to the method of Lapenna et al. (2001).

Lipoprotein isolation: lipoproteins were isolated from plasma by ultracentrifugation in a density gradient, specifically adapted for the hamster (Ferezou et al. 1997) and modified by Morise et al. (2004b). The density limits $(d)$ were as described previously (Morise et al. 2004b), i.e. VLDL, $d<1 \cdot 010$; intermediate-density lipoprotein, $1.010<d<1.015$; LDL, $1.015<d<1.050$; and HDL, $1.050<d<1.190$. In each lipoprotein class, TC, FC, PL and TG were assayed as in plasma, and proteins were determined by the method of Lowry et al. (1951) using bovine serum albumin as standard. Lipoprotein concentrations were calculated by summing up the concentrations of the individual protein and lipid components.

Bile and liver lipids composition: biliary PL and TC were assayed with the same procedures as described above for plasma lipids, after bile dilution in distilled water $(1: 10)$. Bile acids were determined by an enzymatic manual procedure after bile dilution in distilled water $(1: 20)$ (Turley \& Dietschy, 1978). Lithogenic index was calculated as described previously (Morise et al. 2004b).

Hepatic lipids were determined as described above for plasma lipids after extraction in isopropanol from a $150 \mathrm{mg}$ liver sample as described by Loison et al. (2002). The pellet was kept and dissolved in $1 \mathrm{M}-\mathrm{NaOH}$ for further determination of hepatic proteins according to Lowry et al. (1951).

Enzyme activities. Hepatic hydroxymethyl-glutaryl CoA reductase (EC 1.1.1.34) activity was determined in 
microsomal fractions in the presence of alkaline phosphatase using Phillip and Shapiro's radioisotopic technique (Philipp \& Shapiro, 1979).

The activity of the key enzymes of fatty acid oxidation, carnitine palmitoyl transferase (CPT, EC 2.3.1.21) and acyl CoA oxidase (ACO, EC 1.3.3.6), was determined in the hepatic mitochondrial-peroxisomal fraction. CPT activity was also determined in a muscle homogenate as described by Takada et al. (1994). Total mitochondrial CPT activity was measured according to Bieber et al. (1972). Briefly, the assay is based on the spectrophotometric measurement of reduced CoA resulting from the transformation of palmitoyl CoA into palmitoylcarnitine, which is catalysed by CPT. ACO activity was measured according to Lazarow \& De Duve (1976). The assay is based on the measurement of the NADH produced when an acyl CoA is oxidized by ACO. Potassium cyanate was added to the media in order to inhibit mitochondrial oxidation and to measure the peroxisomal activity only. CPT activity was also determined in a muscle homogenate as described by Takada et al. (1994).

Activities of the lipogenic enzymes were determined in the liver as described by Mourot et al. (2000). Briefly, tissues were homogenized in $0.25 \mathrm{M}$-sucrose and centrifuged at $40000 \mathrm{~g}$ for $40 \mathrm{~min}$. The supernatant cytosolic fractions were analysed for malic enzyme (EC 1.1.1.40) and glucose-6-phosphate dehydrogenase (G6PDH; EC 1.1.1.49) using modifications (Gandemer et al. 1983) of the methods of Fitch et al. (1959) and Hsu \& Lardy (1969), respectively. Acetyl CoA carboxylase (ACC; EC 6.4.1.2) was assayed by the $\mathrm{H}^{14} \mathrm{CO}_{3^{-}}$ fixation method (Chang et al. 1967; Chakrabarty \& Leveille, 1969). Fatty acid synthase (FAS; EC 2.3.1.85) was measured as described by Lavau et al. (1982). FAS, malic enzyme and G6PDH activities were expressed as $\mu \mathrm{mol}$ NADPH produced or used per min per total liver and per mg protein. ACC activity was expressed as nmol bicarbonate incorporated per min per total liver and per $\mathrm{mg}$ of protein.

Lipoprotein receptor quantification. Relative hepatic amounts of LDL receptor and scavenger receptor class B type I (SR-BI), shown to be an HDL receptor (Acton et al. 1996), were determined as described previously (Milliat et al. 2000). Briefly, Western blots of membrane proteins from hamster liver were performed using polyclonal antibodies raised in the rabbit against the LDL receptor of the bovine adrenal cortex (gift from P. Roach, Adelaide, Australia) and against the terminal part of murine SR-BI (fifteen amino acids, gift from A. Mazur, Theix, France). The detection was achieved in a chemiluminescence reagent (ECL; Amersham, Little Chalfont, UK). Films were scanned with a laser densitometer (Ultroscan 2222; LKB, Bromma, Sweden). Peak areas allowed quantification of the antigen response. Receptor levels were expressed in arbitrary units, and the value 100 was arbitrarily attributed to the group with the highest value.

RNA analysis. Total RNA was isolated from liver using a TRIzol kit (Invitrogen, Carlsbad, CA, USA) adapted from the Chomczynski and Sacchi method (Chomczynski et al. 1986). cDNA was synthesized from $1 \mu \mathrm{g}$ total RNA using RT Superscript II RNase (Invitrogen) in the conditions described by the manufacturers. To check whether any contamination with genomic DNA occurred, a control without RT Superscript II was included for each RNA sample. Real-time quantitative RT-PCR analyses were performed starting with $25 \mathrm{ng}$ reverse-transcribed total RNA, in a final volume of $20 \mu \mathrm{l}$, using a qPCR Master Mix for Sybr Green I No ROX kit (Eurogentech, Angers, France) in a thermocycler MyiQ Real Time detection system (Biorad, Marnes-La-Coquette, France). Optimized PCR consisted of forty cycles of amplification $\left(95^{\circ} \mathrm{C}\right.$ for $30 \mathrm{~s}, 60^{\circ} \mathrm{C}$ for $30 \mathrm{~s}$ and $72^{\circ} \mathrm{C}$ for $\left.30 \mathrm{~s}\right)$. Relative quantification for a given gene was calculated after normalization to $18 \mathrm{~S}$ ribosomal RNA. Design of specific primers was performed using Applied Biosystem (Foster City, Canada) software. Sense and antisense primers were: GAGAAAGCAAAACTGAAAGCAGAGA and GAAGGGCGGGTTATTGCTG for PPAR $\alpha$, CACTCCCATTCCTTTGACATCA and AGCTGGGCCTTTTCAGAATAATAA for PPAR $\gamma$; GAACATCTCTTGGAGAGAGCACTG and GGTGGAAGCCATGCTGGA for sterol response element binding protein 1c (SREBP1c); TGATGATGGGACAAGAGAAAGTTC and TTTGTGCATCTTGGCATCTGTT for SREBP2, GTGGGCCTGCGGCTTAAT and GCCAGAGTCTCGTTCGTTATC for 18S; GCAACTCAATGATGCCGAGTT and CGTGGGAACATCAGTCGGTC for liver X receptor $\alpha$; and AGGCTGCAAGGCTTTCTTCA and CTCTCCGGTCTTTCCGTATCC for oestrogen receptor.

\section{Statistical analyses}

Power analysis was calculated on the basis of a two-way ANOVA by using the Power and Precision program (SPSS Inc., Chicago, IL, USA). Main outcome values were plasma risk factors of metabolic syndrome and CVD, i.e. concentrations of TG, CH, LDL-CH and HDL-CH. Data were analysed using the Statview 4.5 program (Abacus Concept, Berkeley, CA, USA). Differences between treatments were assayed with a two-way ANOVA with diet and gender as factors. Differences between means of the four groups were determined by post hoc Fisher test and considered to be significant at $P<0 \cdot 05$.

\section{Results}

\section{Body weight and adiposity}

At the beginning of the experiment ( 8 weeks of age), males were $6 \%$ heavier than females, whereas they were $19 \%$ lighter at the end (13 weeks of age) (Table 2). As a consequence, body weight gain was much more important for females than males (43 v. $17 \mathrm{~g}$ ). Diet, however, affected neither body weight, nor the total and relative weight of gonadal adipose tissue.

\section{Fatty acid incorporation into erythrocytes}

As expected, the fatty acid profile of erythrocyte PL exhibited a high PUFA content $(40 \%)$, most of them from the $n-6$ family (Table 3). Diet influenced the proportion of all fatty acids: in animals fed the 'butter' diet, SFA, MUFA, n-6 PUFA (LA) and more surprisingly DHA, were in higher proportion than in those fed the 'linseed oil' diet, whereas total PUFA, LA and $n-3$ PUFA (except DHA) were in lower proportion. Gender also affected the fatty acid profile of erythrocytes. Females exhibited higher percentages than males of total SFA, ALA and $22: 5 n-3$, and lower percentages of 
Table 2. Effect of gender and diet on body weight gain and adiposity*

(Mean values with their standard errors for nine hamsters per group)

\begin{tabular}{|c|c|c|c|c|c|c|c|c|c|c|c|}
\hline & \multicolumn{4}{|c|}{ Females } & \multicolumn{4}{|c|}{ Males } & & & \\
\hline & \multicolumn{2}{|c|}{ 'Butter' } & \multicolumn{2}{|c|}{ 'Linseed oil' } & \multicolumn{2}{|c|}{ 'Butter' } & \multicolumn{2}{|c|}{ 'Linseed oil' } & \multicolumn{3}{|c|}{ Effects† } \\
\hline Initial body wt (g) & $85 \cdot 4^{\mathrm{b}}$ & $1 \cdot 7$ & $84 \cdot 7^{\mathrm{b}}$ & $1 \cdot 3$ & $91 \cdot 1^{\mathrm{a}}$ & 0.9 & $90 \cdot 8^{a}$ & $1 \cdot 7$ & $<0.001$ & 0.894 & 0.747 \\
\hline Final body wt $(\mathrm{g})$ & $128^{a}$ & 2 & $129^{a}$ & 3 & $111^{\mathrm{b}}$ & 3 & $105^{\mathrm{b}}$ & 2 & $<0.001$ & 0.344 & 0.186 \\
\hline EAT or PUAT wt $(\mathrm{g})$ & $1.08^{\mathrm{b}}$ & 0.11 & $1 \cdot 21^{\mathrm{ab}}$ & 0.13 & $1.52^{a}$ & 0.14 & $1 \cdot 34^{\mathrm{ab}}$ & 0.08 & 0.021 & 0.854 & 0.201 \\
\hline
\end{tabular}

EAT, epididymal adipose tissue; PUAT, periuterine adipose tissue.

${ }^{\star}$ For details of procedures and diets, see pp. $710-711$ and Table 1.

$\dagger \mathrm{G}, \mathrm{D}$ and $\mathrm{I}$ are the effects of gender, diet and interaction between both treatments after two-way ANOVA.

${ }_{\mathrm{ab}}$ Mean values within a row with unlike superscript letters were significantly different $(P<0.05)$.

MUFA, $n-6$ PUFA, $22: 5 n-6$, LA and EPA. However, as concerns $n-3$ PUFA (except DHA), most of these gender-related effects were more pronounced in animals fed the 'linseed oil' diet.

As expected, LA:ALA, arachidonic acid (AA):EPA and $n-6: n-3$ PUFA ratios were higher in animals fed the 'butter' diet than in those fed the 'linseed oil' diet. Moreover, LA:ALA and $n-6: n-3$ PUFA ratios, but not the AA:EPA ratio, were also higher in males than in females.

\section{Plasma parameters}

Plasma TG concentration was not affected by gender (Fig. 1(A)). It was lower in animals fed the 'linseed oil' diet than in those fed the 'butter' one, and the difference was more pronounced in males $(-58 \%)$ than in females $(-14 \%)$. The variation in VLDL-TG concentration tended to parallel that of total TG, but the differences were not significant. LDL-TG concentration was not responsive to diet, but was lower in males than in females. This difference was essentially due to the males fed the 'linseed oil' diet, in which LDL-TG concentration was about $40 \%$ lower than in the three other groups. As for HDL$\mathrm{TG}$, neither gender nor diet influenced their concentration. $\mathrm{CH}$ concentration was affected by gender mainly (Fig. 1(B)), males exhibiting higher plasma $\mathrm{CH}(+22 \%)$, LDL-CH $(+81 \%)$ and HDL-CH $(+19 \%)$ and lower VLDL-CH concentration $(-22 \%)$ than females. Diet affected only HDL-CH concentration that was lower in 'linseed oil'-fed animals, and the difference was more pronounced in males than in females $(-13 \%$ v. $-3 \%)$. PL concentration paralleled that of $\mathrm{CH}$; males exhibited higher values of total PL $(+18 \%)$, LDL-PL $(+62 \%)$ and HDL-PL $(+18 \%)$ and lower values of VLDLPL $(-28 \%)$ than females (Fig. 1(C)). Moreover, diet affected plasma-, LDL- and HDL-PL concentrations which were,

Table 3. Effect of gender and diet on fatty acid composition of erythrocytes (as \% total fatty acids)* (Mean values with their standard errors for nine hamsters per group)

\begin{tabular}{|c|c|c|c|c|c|c|c|c|c|c|c|}
\hline & \multicolumn{4}{|c|}{ Females } & \multicolumn{4}{|c|}{ Males } & & & \\
\hline & \multicolumn{2}{|c|}{ 'Butter' } & \multicolumn{2}{|c|}{ 'Linseed oil' } & \multicolumn{2}{|c|}{ 'Butter' } & \multicolumn{2}{|c|}{ 'Linseed oil' } & \multicolumn{3}{|c|}{ Effects† } \\
\hline & Mean & SEM & Mean & SEM & Mean & SEM & Mean & SEM & $\mathrm{G}$ & D & 1 \\
\hline$\Sigma S F A$ & $40 \cdot 97^{a}$ & 0.56 & $39 \cdot 75^{a b}$ & 0.46 & $39 \cdot 17^{b}$ & 0.25 & $38.54^{b}$ & 0.47 & 0.021 & 0.047 & 0.510 \\
\hline ¿MUFA & $18 \cdot 29^{b c}$ & 0.17 & $17 \cdot 88^{c}$ & $0 \cdot 18$ & $19 \cdot 33^{a}$ & 0.16 & $18 \cdot 59^{b}$ & $0 \cdot 19$ & $<0.001$ & 0.003 & 0.369 \\
\hline $18: 1 n-9$ & $13 \cdot 19^{b}$ & 0.08 & $12 \cdot 59^{c}$ & 0.13 & $13 \cdot 91^{\mathrm{a}}$ & 0.16 & $13 \cdot 28^{b}$ & 0.16 & $<0.001$ & $<0.001$ & 0.907 \\
\hline$\Sigma n-6$ & $33 \cdot 10^{b}$ & 0.36 & $29 \cdot 37^{d}$ & 0.30 & $34.08^{a}$ & 0.18 & $30 \cdot 72^{c}$ & 0.21 & $<0.001$ & $<0.001$ & 0.493 \\
\hline $18: 2 n-6$ & $15 \cdot 93^{d}$ & 0.17 & $17 \cdot 29^{b}$ & $0 \cdot 19$ & $16 \cdot 49^{c}$ & 0.17 & $18 \cdot 39^{a}$ & $0 \cdot 16$ & $<0.001$ & $<0.001$ & 0.131 \\
\hline $20: 4 n-6$ & $12 \cdot 80^{\mathrm{a}}$ & 0.20 & $9 \cdot 63^{b}$ & 0.16 & $13 \cdot 24^{a}$ & 0.18 & $9 \cdot 92^{b}$ & 0.22 & 0.068 & $<0.001$ & 0.693 \\
\hline $22: 4 n-6$ & $2 \cdot 61^{a}$ & 0.08 & $0.84^{b}$ & 0.04 & $2 \cdot 60^{\mathrm{a}}$ & 0.04 & $0.94^{b}$ & 0.05 & 0.363 & $<0.001$ & 0.332 \\
\hline $22: 5 n-6$ & $0.37^{a}$ & 0.02 & $0 \cdot 15^{\mathrm{b}}$ & 0.01 & $0.39^{a}$ & 0.01 & $0 \cdot 17^{\mathrm{b}}$ & 0.01 & 0.040 & $<0.001$ & 0.752 \\
\hline$\sum n-3$ & $6 \cdot 84^{c}$ & 0.19 & $12 \cdot 52^{a}$ & 0.21 & $6 \cdot 70^{c}$ & 0.13 & $11 \cdot 79^{b}$ & 0.34 & 0.069 & $<0.001$ & 0.214 \\
\hline $18: 3 n-3$ & $0 \cdot 16^{c}$ & 0.00 & $3.04^{a}$ & 0.04 & $0.15^{\mathrm{c}}$ & 0.00 & $2 \cdot 77^{\mathrm{b}}$ & 0.04 & $<0.001$ & $<0.001$ & $<0.001$ \\
\hline $20: 5 n-3$ & $0.40^{c}$ & 0.01 & $1 \cdot 64^{b}$ & 0.03 & $0.44^{c}$ & 0.01 & $1 \cdot 77^{\mathrm{a}}$ & 0.06 & 0.022 & $<0.001$ & 0.192 \\
\hline $22: 5 n-3$ & $1 \cdot 32^{c}$ & 0.05 & $4 \cdot 08^{a}$ & 0.07 & $1.53^{c}$ & 0.02 & $3.58^{b}$ & 0.11 & 0.052 & $<0.001$ & $<0.001$ \\
\hline $18: 2 n-6: 18: 3 n-3$ & $102 \cdot 2^{\mathrm{b}}$ & $2 \cdot 3$ & $5 \cdot 7^{\mathrm{C}}$ & 0.1 & $108 \cdot 2^{a}$ & $2 \cdot 1$ & $6 \cdot 6^{\mathrm{C}}$ & 0.1 & 0.033 & $<0.001$ & 0.114 \\
\hline$n-6: n-3$ & $4 \cdot 86^{\mathrm{b}}$ & 0.11 & $2 \cdot 35^{d}$ & 0.04 & $5 \cdot 10^{\mathrm{a}}$ & $0 \cdot 1$ & $2 \cdot 62^{c}$ & 0.07 & 0.004 & $<0.001$ & 0.829 \\
\hline AA : EPA & $31 \cdot 88^{a}$ & 0.77 & $5 \cdot 90^{\mathrm{b}}$ & $0 \cdot 11$ & $30 \cdot 21^{a}$ & 1.08 & $5 \cdot 62^{b}$ & $0 \cdot 13$ & $0 \cdot 152$ & $<0.001$ & 0.303 \\
\hline
\end{tabular}

AA, arachidonic acid; SFA, saturated fatty acids.

${ }^{*}$ For details of procedures and diets, see pp. 710-711 and Table 1.

$\dagger \mathrm{G}, \mathrm{D}$ and $\mathrm{I}$ are the effects of gender, diet and interaction between both treatments after two-way ANOVA.

abc Mean values within a row with unlike superscript letters were significantly different $(P<0.05)$. 

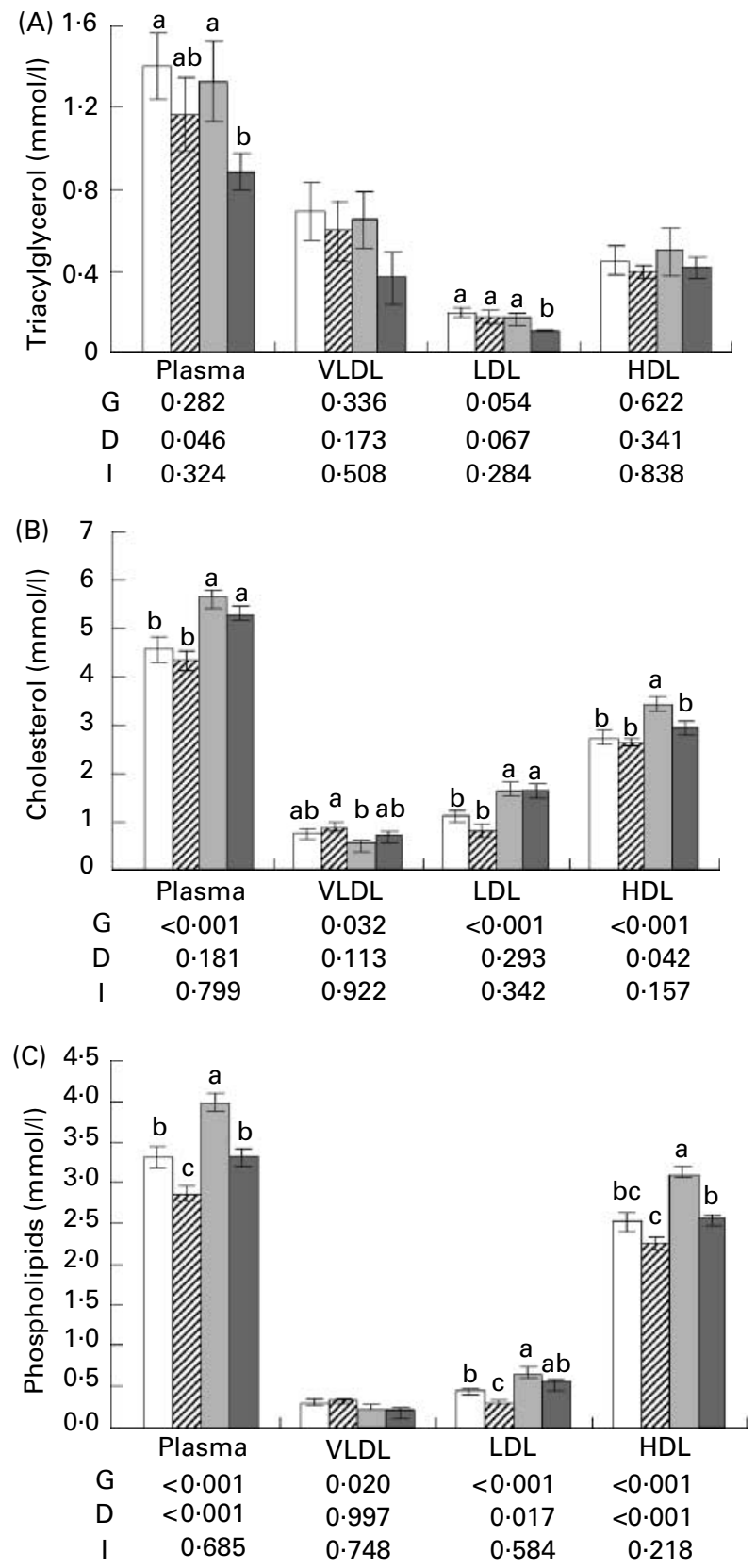

Fig. 1. Distribution of plasma triacylglycerol (A), total cholesterol (B) and phospholipids $(C)$ in lipoprotein fractions obtained by density-gradient ultracentrifugation of plasma from females fed the 'butter' diet ( $\square$ ), females fed the 'linseed oil' diet $(\mathbb{Q})$, males fed the 'butter' diet $(\square)$ and males fed the 'linseed oil' diet $(\square)$. For details of procedures, see pp. 710-711. Values are means with their standard errors depicted by vertical bars (nine hamsters per group). ${ }^{a, b}$ Mean values with unlike superscript letters were significantly different $(P<0.05)$. D, effect of diet (butter $v$. linseed); $\mathrm{G}$, effect of gender (females $v$. males); I, interaction between gender and diet effects.

respectively, 15, 24 and $14 \%$ higher in animals fed the 'butter' diet.

These effects of gender and diet on plasma lipids were the reflection of differences in concentration and composition of lipoproteins (Table 4). Plasma VLDL concentration was significantly affected neither by gender nor by diet. In contrast, its composition was responsive to the diet. Whereas VLDL from hamsters fed the 'butter' diet contained as expected mostly
TG, those from hamsters fed the 'linseed oil' diet were enriched in CE $(+40 \%)$ to the detriment of TG. Therefore, the main lipid component of the VLDL core was TG in animals fed the 'butter' diet and CE in those fed the 'linseed oil' one, whereas the sum of TG and CE proportions remained the same $(70 \%)$ in both groups. In contrast to VLDL, LDL were influenced by gender: in males, LDL were in higher concentration than in females and they were richer in CE $(43.6 \% v .38 .6 \%)$ and poorer in TG $(4.25 \% v \cdot 10.7 \%)$. Moreover, these gender-related differences were more pronounced in animals fed the 'linseed oil' diet. Plasma total HDL concentration was affected by both gender and diet, mostly because it was $25 \%$ higher in males fed the 'butter' diet than in the other three groups. HDL composition was affected neither by gender nor by the diet.

As a result of concomitant variations due to gender and diet in lipoprotein concentration and composition, the non-HDL-CH:HDL-CH ratio was identical in all groups.

Glycaemia was affected by both gender and diet (Table 5). It was $10 \%$ higher in females than in males and $11 \%$ higher in hamsters fed the 'butter' diet than in those fed the 'linseed oil' one. As a consequence, females fed the 'butter' diet were markedly hyperglycaemic when compared to the other three groups. Insulinaemia and HOMA, the insulin resistance index, did not differ with gender and were, respectively, 71 and $87 \%$ higher in animals fed the 'butter' diet than in those fed the 'linseed oil' one. As concerns oxidative status in plasma, the concentration of malondialdehyde (a product of peroxidation) was $28 \%$ higher in females fed the 'butter' diet than in the three other groups. Vitamin E concentration in plasma was $36 \%$ lower in hamsters fed the 'linseed oil' diet than in those fed the 'butter' diet, regardless of gender. It was also affected by gender, but only in animals fed the 'butter' diet, in which females exhibited $20 \%$ lower plasma vitamin $\mathrm{E}$ concentration than males.

\section{Liver and bile composition}

Total liver weight (in g), was $9 \%$ lower in males than in females, and this difference was more pronounced in the 'linseed oil' diet (Table 6). However, when expressed as a percentage of total body weight, the liver proportion was $9 \%$ higher in males than in females, especially in those fed the 'butter' diet. Hepatic CE and TG content were, respectively, 52 and $37 \%$ higher in males than in females and, respectively, 26 and $22 \%$ higher in animals fed the 'butter' diet than in those fed the 'linseed oil' one. FC and PL contents were 35 and $7 \%$ higher in males than in females. These effects remained the same when the results were expressed as mmol per mg proteins or per whole liver (data not shown).

Bile concentrations of TC and PL were, respectively, 52 and $33 \%$ higher in males than in females and were 18 and $49 \%$ higher in animals fed the 'linseed oil' diet than in those fed the 'butter' one. Bile acid concentration tended to be higher in males and was not affected by the diet. All these effects resulted in a higher lithogenic index in males.

\section{Cholesterol absorption and synthesis}

The percentage of absorbed dietary $\mathrm{CH}$ was high in all groups and varied between 77.5 (SEM 0.9) and 83.4 (SEM 2.4), without any effect of gender or diet. 
Table 4. Plasma lipoprotein concentration ( $\mathrm{g} / \mathrm{l})$ and composition (\%) of female and male hamsters fed 'butter' or 'linseed oil' diets* (Mean values with their standard errors for nine hamsters per group)

\begin{tabular}{|c|c|c|c|c|c|c|c|c|c|c|c|}
\hline & \multicolumn{4}{|c|}{ Females } & \multicolumn{4}{|c|}{ Males } & & & \\
\hline & \multicolumn{2}{|c|}{ 'Butter' } & \multicolumn{2}{|c|}{ 'Linseed oil' } & \multicolumn{2}{|c|}{ 'Butter' } & \multicolumn{2}{|c|}{ 'Linseed oil' } & \multicolumn{3}{|c|}{ Effects $†$} \\
\hline VLDL & 1.41 & 0.18 & 1.47 & 0.22 & $1 \cdot 18$ & 0.18 & 1.01 & 0.20 & 0.090 & 0.791 & 0.561 \\
\hline VLDL-FC & 3.90 & 0.36 & $3 \cdot 16$ & 0.41 & $3 \cdot 81$ & 0.35 & 3.99 & 0.32 & 0.317 & 0.449 & 0.214 \\
\hline VLDL-CE & $28 \cdot 85^{\mathrm{b}}$ & 2.39 & $39 \cdot 47^{\mathrm{a}}$ & 3.66 & $27 \cdot 15^{\mathrm{b}}$ & 2.25 & $45 \cdot 77^{a}$ & $4 \cdot 18$ & 0.482 & $<0.001$ & 0.226 \\
\hline VLDL-PL & $17 \cdot 56^{a b}$ & 0.51 & $18 \cdot 00^{\mathrm{a}}$ & 0.76 & $16 \cdot 01^{b}$ & 0.66 & $17 \cdot 96^{\mathrm{a}}$ & 0.68 & 0.234 & 0.078 & 0.259 \\
\hline VLDL-PR & $8 \cdot 37$ & 0.53 & $8 \cdot 18$ & 0.41 & 7.58 & 0.65 & 8.46 & 0.45 & 0.632 & 0.509 & 0.307 \\
\hline LDL & $1.48^{\mathrm{bc}}$ & 0.13 & $1.06^{c}$ & 0.15 & $2 \cdot 14^{\mathrm{a}}$ & 0.24 & $1.91^{\mathrm{ab}}$ & 0.14 & $<0.001$ & 0.066 & 0.561 \\
\hline LDL-FC & 5.59 & 0.35 & 4.83 & 0.21 & $5 \cdot 56$ & 0.31 & $5 \cdot 70$ & 0.41 & 0.855 & 0.724 & 0.895 \\
\hline LDL-CE & $37 \cdot 6^{\mathrm{b}}$ & $1 \cdot 4$ & $38 \cdot 8^{\mathrm{b}}$ & $2 \cdot 0$ & $40 \cdot 6^{\mathrm{ab}}$ & 1.8 & $44 \cdot 8^{a}$ & 1.4 & 0.006 & 0.237 & 0.233 \\
\hline LDL-TG & $12 \cdot 6^{\mathrm{ab}}$ & 2.5 & $15 \cdot 4^{a}$ & 2.5 & $8 \cdot 0^{\mathrm{bc}}$ & 1.4 & $5 \cdot 0^{c}$ & 0.35 & $<0.001$ & 0.974 & 0.134 \\
\hline LDL-PL & $23 \cdot 7$ & 0.9 & $22 \cdot 2$ & $1 \cdot 1$ & 23.5 & 0.6 & 22.5 & 0.6 & 0.909 & 0.128 & 0.749 \\
\hline LDL-PR & $20 \cdot 6$ & 1.6 & 18.9 & 1.3 & $22 \cdot 3$ & 1.5 & $22 \cdot 0$ & $1 \cdot 2$ & 0.096 & 0.493 & 0.637 \\
\hline HDL-CE & $22 \cdot 79^{b}$ & 0.61 & $23.93^{\mathrm{ab}}$ & 0.71 & $23 \cdot 73^{\text {ab }}$ & 0.38 & $24 \cdot 45^{\mathrm{a}}$ & 0.56 & 0.213 & 0.114 & 0.721 \\
\hline HDL-TG & 6.49 & 0.84 & $6 \cdot 23$ & 0.48 & 5.79 & $1 \cdot 15$ & $5 \cdot 90$ & 0.65 & 0.537 & 0.930 & 0.819 \\
\hline HDL-PL & 33.36 & 0.62 & 31.46 & 0.64 & 32.92 & 1.29 & $32 \cdot 39$ & 0.56 & 0.769 & 0.154 & 0.412 \\
\hline HDL-PR & $33 \cdot 13$ & 0.78 & $34 \cdot 61$ & 0.70 & 33.94 & 2.02 & $33 \cdot 28$ & 0.65 & 0.827 & 0.731 & 0.372 \\
\hline Non-HDL-TC : HDL-TC & 0.68 & 0.06 & 0.64 & 0.06 & 0.67 & 0.07 & 0.78 & 0.04 & 0.280 & 0.488 & 0.178 \\
\hline
\end{tabular}

CE, cholesteryl esters; FC, free cholesterol; PL, phospholipids; PR, proteins; TC, total cholesterol; TG, triacylglycerols.

${ }^{*}$ For details of procedures and diets, see pp. 710-711 and Table 1.

$+G, D$ and I are the effects of gender, diet and interaction between both treatments after two-way ANOVA.

${ }^{\mathrm{abc}}$ Mean values within a row with unlike superscript letters were significantly different $(P<0.05)$.

As compared to the 'butter' diet, the 'linseed oil' diet provoked an increase in hydroxymethyl-glutaryl CoA reductase specific activity but this effect was significant in females only (Table 7). Expressed as total activity in the whole liver, the diet effect was still significant and due to the females fed the 'linseed oil' diet, which exhibited a $27 \%$ lower activity than the other three groups (data not shown).

\section{Fatty acid synthesis and oxidation}

Specific and total activities per liver of key enzymes of lipogenesis are reported in Table 7. ACC and FAS specific activities were affected neither by gender nor by diet. Since the liver was heavier in females than in males, total ACC activity was higher in the former. FAS tended to respond like ACC, although neither differences between groups nor the gender effect were significant. In contrast, malic enzyme, a NADPH provider, was affected by both gender and diet. Males had more than twice higher specific and total activities than females, and the gender effect was more pronounced in animals fed the 'butter' diet. Moreover, animals fed the 'linseed oil' diet exhibited about $50 \%$ weaker activities than those fed the 'butter' one, the diet effect being more pronounced in males. The activity of G6PDH, another NADPH provider, was 2-3-fold weaker than that of malic enzyme. Expressed as specific activity or per total liver, G6PDH was not affected by any treatment.

Specific hepatic activity of ACO was lowered by the 'linseed oil' diet but only in males $(-20 \%$; Table 7$)$. By contrast, specific activity of CPT was higher in animals fed the 'linseed oil' diet than in those fed the 'butter' one and this

Table 5. Effect of gender and diet on glycaemic and oxidative status* (Mean values with their standard errors for nine hamsters per group)

\begin{tabular}{|c|c|c|c|c|c|c|c|c|c|c|c|}
\hline & \multicolumn{4}{|c|}{ Females } & \multicolumn{4}{|c|}{ Males } & & & \\
\hline & \multicolumn{2}{|c|}{ 'Butter' } & \multicolumn{2}{|c|}{ 'Linseed oil' } & \multicolumn{2}{|c|}{ 'Butter' } & \multicolumn{2}{|c|}{ 'Linseed oil' } & \multicolumn{3}{|c|}{ Effects† } \\
\hline & Mean & SEM & Mean & SEM & Mean & SEM & Mean & SEM & $\mathrm{G}$ & $\mathrm{D}$ & I \\
\hline Glucose $(\mathrm{mmol} / \mathrm{l})$ & $6 \cdot 44^{a}$ & 0.20 & $5 \cdot 69^{b}$ & 0.22 & $5 \cdot 77^{\mathrm{b}}$ & 0.19 & $5 \cdot 29^{b}$ & 0.20 & 0.020 & 0.007 & 0.649 \\
\hline Insulin (mU/l) & $35 \cdot 3^{a b}$ & $5 \cdot 6$ & $25 \cdot 6^{\mathrm{bc}}$ & $4 \cdot 2$ & $38 \cdot 3^{a}$ & $4 \cdot 8$ & $17 \cdot 5^{\mathrm{c}}$ & 1.8 & 0.467 & $<0.001$ & 0.224 \\
\hline HOMA & $10 \cdot 34^{a}$ & 1.59 & $6 \cdot 55^{\mathrm{bc}}$ & $1 \cdot 13$ & $9 \cdot 82^{a b}$ & $1 \cdot 22$ & $4 \cdot 20^{C}$ & 0.55 & 0.234 & $<0.001$ & 0.448 \\
\hline Vitamin E (pmol/ $\mu \mathrm{l})$ & $81 \cdot 0^{\mathrm{b}}$ & $5 \cdot 0$ & $58 \cdot 2^{\mathrm{c}}$ & $2 \cdot 0$ & $100 \cdot 7^{a}$ & $5 \cdot 7$ & $58 \cdot 1^{\mathrm{c}}$ & $2 \cdot 2$ & 0.022 & $<0.001$ & 0.021 \\
\hline MDA ( $\mu \mathrm{mol} / / \mathrm{T}$ TBARS) & $1 \cdot 84^{a}$ & 0.08 & $1 \cdot 39^{b}$ & 0.12 & $1.46^{\mathrm{b}}$ & 0.12 & $1.46^{\mathrm{b}}$ & 0.06 & 0.126 & 0.030 & 0.029 \\
\hline
\end{tabular}

HOMA, homeostasis model assessment; MDA, malondialdehyde; TBARS, thiobarbituric acid reactive substances.

${ }^{*}$ For details of procedures and diets, see pp. 710-711 and Table 1.

$\dagger G, D$ and $I$ are the effects of gender, diet and interaction between both treatments after two-way ANOVA.

abc Mean values within a row with unlike superscript letters were significantly different $(P<0.05)$. 
Table 6. Effect of gender and diet on composition of liver and bile*

(Mean values with their standard errors for nine hamsters per group)

\begin{tabular}{|c|c|c|c|c|c|c|c|c|c|c|c|}
\hline & \multicolumn{4}{|c|}{ Females } & \multicolumn{4}{|c|}{ Males } & & & \\
\hline & \multicolumn{2}{|c|}{ 'Butter' } & \multicolumn{2}{|c|}{ ‘Linseed oil' } & \multicolumn{2}{|c|}{ 'Butter’ } & \multicolumn{2}{|c|}{ ‘Linseed oil' } & \multicolumn{3}{|c|}{ Effects† } \\
\hline Liver wt (g) & $4 \cdot 51^{a}$ & 0.12 & $4 \cdot 71^{\mathrm{a}}$ & 0.17 & $4.42^{\mathrm{a}}$ & 0.18 & $3.99^{b}$ & 0.05 & 0.007 & 0.425 & 0.033 \\
\hline Liver wt (\% body wt) & $3.52^{c}$ & 0.06 & $3.65^{\mathrm{bc}}$ & 0.09 & $3.98^{a}$ & 0.08 & $3 \cdot 81^{\mathrm{ab}}$ & 0.05 & $<0.001$ & 0.703 & 0.046 \\
\hline \multicolumn{12}{|l|}{ Liver $(\mu \mathrm{mol} / \mathrm{g})$} \\
\hline $\mathrm{FC}$ & $6 \cdot 0^{c}$ & 0.2 & $6 \cdot 3^{c}$ & 0.3 & $8 \cdot 9^{a}$ & 0.5 & $7 \cdot 7^{\mathrm{b}}$ & 0.3 & $<0.001$ & 0.302 & 0.049 \\
\hline $\mathrm{CE}$ & $49 \cdot 1^{c}$ & $1 \cdot 7$ & $43 \cdot 0^{c}$ & $3 \cdot 2$ & $79 \cdot 9^{a}$ & $3 \cdot 6$ & $59 \cdot 1^{b}$ & 3.5 & $<0.001$ & $<0.001$ & 0.025 \\
\hline $\mathrm{TG}$ & $10 \cdot 0^{\mathrm{bc}}$ & 0.9 & $8 \cdot 6^{\mathrm{C}}$ & 0.3 & $14 \cdot 2^{a}$ & $1 \cdot 3$ & $11 \cdot 3^{b}$ & 0.9 & $<0.001$ & 0.026 & 0.414 \\
\hline PL & $23 \cdot 4^{\mathrm{c}}$ & 0.3 & $24 \cdot 0^{\mathrm{ab}}$ & 0.4 & $25 \cdot 3^{a}$ & 0.9 & $25 \cdot 3^{a}$ & 0.5 & 0.011 & 0.607 & 0.532 \\
\hline \multicolumn{12}{|l|}{ Bile $(\mathrm{mmol} / \mathrm{l})$} \\
\hline TC & $1 \cdot 84^{b}$ & 0.18 & $2 \cdot 15^{\mathrm{b}}$ & 0.14 & $2 \cdot 77^{a}$ & 0.15 & $3 \cdot 30^{\mathrm{a}}$ & 0.24 & $<0.001$ & 0.030 & 0.562 \\
\hline PL & $9.59^{c}$ & 1.39 & $15 \cdot 1^{\mathrm{b}}$ & 1.31 & $17 \cdot 4^{\mathrm{b}}$ & $1 \cdot 1$ & $25 \cdot 1^{\mathrm{a}}$ & 1.7 & $<0.001$ & $<0.001$ & 0.420 \\
\hline BA & $142^{\mathrm{b}}$ & 14 & $160^{\mathrm{ab}}$ & 15 & $169^{\mathrm{ab}}$ & 9 & $171^{\mathrm{a}}$ & 8 & 0.068 & 0.328 & 0.441 \\
\hline
\end{tabular}

BA, bile acid; CE, cholesteryl esters; FC, free cholesterol; LI, lithogenic index (a ratio, thus without unit); PL, phospholipids; TC, total cholesterol; TG, triacylglycerols.

${ }^{*}$ For details of procedures and diets, see pp. 710-711 and Table 1.

$\dagger \mathrm{G}, \mathrm{D}$ and $\mathrm{I}$ are the effects of gender, diet and interaction between both treatments after two-way ANOVA.

${ }^{\text {abc }}$ Mean values within a row with unlike superscript letters were significantly different $(P<0.05)$.

was more pronounced in males $(+130 \%)$ than in females $(+40 \%)$. As in the liver, specific CPT activity in the muscle was higher in animals fed the 'linseed oil' diet than in those fed the 'butter' one, but in males only $(+16 \%)$.

Total ACO activity in whole liver was higher in animals fed the 'linseed oil' diet than in those fed the 'butter' one
(Table 7). Total CPT activity in whole liver was affected by both gender and diet: it doubled in animals fed the 'linseed oil' diet compared to those fed the 'butter' one. The gender effect was essentially due to the males fed the 'linseed oil' diet that exhibited about $100 \%$ higher activities than the other three groups. Total CPT in whole muscle was affected neither by gender nor by diet. However, a significant

Table 7. Activity of enzymes involved in cholesterol and fatty acid synthesis and oxidation in liver and muscle*

(Mean values with their standard errors for nine hamsters per group)

\begin{tabular}{|c|c|c|c|c|c|c|c|c|c|c|c|}
\hline \multirow{2}{*}{ Tissues and enzymes } & \multicolumn{4}{|c|}{ Females } & \multicolumn{4}{|c|}{ Males } & & & \\
\hline & \multicolumn{2}{|c|}{ 'Butter' } & \multicolumn{2}{|c|}{ 'Linseed oil' } & \multicolumn{2}{|c|}{ 'Butter' } & \multicolumn{2}{|c|}{ ‘Linseed oil’ } & \multicolumn{3}{|c|}{ Effects $†$} \\
\hline \multicolumn{12}{|l|}{ Liver (nmol/min per mg protein) } \\
\hline HMGCoA-R & $9 \cdot 21^{a}$ & 0.69 & $6 \cdot 27^{\mathrm{b}}$ & 0.40 & $9 \cdot 17^{\mathrm{a}}$ & 0.66 & $8 \cdot 92^{\mathrm{a}}$ & 0.51 & 0.030 & 0.010 & 0.025 \\
\hline $\mathrm{ACC}$ & 0.77 & $0 \cdot 19$ & 0.62 & $0 \cdot 11$ & 0.47 & 0.07 & 0.48 & 0.08 & 0.082 & 0.576 & 0.547 \\
\hline ME & $0.21^{b}$ & 0.04 & $0 \cdot 12^{b}$ & 0.02 & $0.57^{a}$ & 0.13 & $0.31^{\mathrm{b}}$ & 0.06 & $<0.001$ & 0.023 & 0.277 \\
\hline G6PDH & 0.07 & 0.01 & 0.07 & 0.01 & 0.07 & 0.01 & 0.09 & 0.02 & 0.248 & 0.373 & 0.327 \\
\hline $\mathrm{ACO}$ & $23 \cdot 6^{\mathrm{a}}$ & 0.9 & $26 \cdot 4^{\mathrm{a}}$ & 1.6 & $24 \cdot 0^{\mathrm{a}}$ & $1 \cdot 0$ & $19 \cdot 5^{\mathrm{b}}$ & 0.6 & 0.007 & 0.457 & 0.002 \\
\hline СРТ & $3.86^{\mathrm{b}}$ & 0.48 & $5.47^{\mathrm{b}}$ & 0.64 & $2 \cdot 91^{\mathrm{b}}$ & 0.38 & $6 \cdot 60^{\mathrm{a}}$ & $1 \cdot 34$ & 0.690 & $<0.001$ & 0.057 \\
\hline \multicolumn{12}{|l|}{ Liver (nmol/min per liver) } \\
\hline HMGCoA-R & $956^{a}$ & 76 & $653^{b}$ & 39 & $881^{a}$ & 69 & $853^{a}$ & 60 & 0.327 & 0.012 & 0.034 \\
\hline ACC & $454^{a}$ & 91 & $393^{\mathrm{ab}}$ & 64 & $236^{\mathrm{bc}}$ & 35 & $195^{\mathrm{C}}$ & 29 & 0.003 & 0.504 & 0.982 \\
\hline FAS & 461 & 52 & 423 & 55 & 407 & 51 & 329 & 39 & 0.147 & 0.250 & 0.697 \\
\hline $\mathrm{ACO}$ & 1442 & 70 & 1601 & 73 & 1455 & 49 & 1567 & 64 & 0.871 & 0.045 & 0.723 \\
\hline $\mathrm{CPT}$ & $241^{b}$ & 36 & $333^{b}$ & 39 & $181^{\mathrm{b}}$ & 27 & $533^{a}$ & 92 & 0.049 & $<0.001$ & 0.002 \\
\hline \multicolumn{12}{|l|}{ Vastus lateralis muscle } \\
\hline $\begin{array}{l}\text { CPT (nmol/min per mg } \\
\text { protein) }\end{array}$ & $6 \cdot 24^{b}$ & 0.41 & $6 \cdot 34^{\mathrm{b}}$ & 0.24 & $6 \cdot 97^{b}$ & 0.30 & $8 \cdot 11^{\mathrm{a}}$ & 0.30 & $<0.001$ & 0.059 & 0.114 \\
\hline CPT (nmol/min per muscle) & $257^{\mathrm{b}}$ & 17 & $266^{\mathrm{b}}$ & 20 & $298^{b}$ & 17 & $353^{a}$ & 26 & 0.094 & 0.079 & 0.028 \\
\hline
\end{tabular}

ACC, acetyl CoA carboxylase; ACO, acyl CoA oxidase; CPT, carnitine palmitoyl transferase; FAS, fatty acid synthase; G6PDH, glucose-6-phosphate dehydrogenase; HMGCoA-R, hydroxymethyl-glutaryl CoA reductase; ME, malic enzyme.

${ }^{*}$ For details of procedures and diets, see pp. 710-711 and Table 1.

$\dagger G, D$ and $I$ are the effects of gender, diet and interaction between both treatments after two-way ANOVA.

${ }^{\mathrm{abc}}$ Mean values within a row with unlike superscript letters were significantly different $(P<0.05)$. 


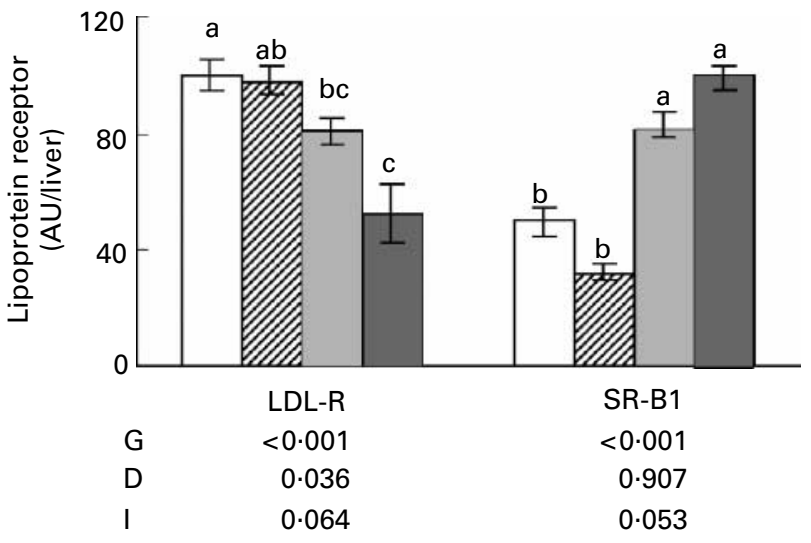

Fig. 2. Quantity of LDL and HDL receptor in the liver, obtained by Western blot, of females fed the 'butter' diet $(\square)$, females fed the 'linseed oil' diet (包), males fed the 'butter' diet $(\square)$ and males fed the 'linseed oil' diet ( $\square$ ). For details of procedures, see pp. 710-711. Values are means with their standard errors depicted by vertical bars (nine hamsters per group). ${ }^{a, b}$ Mean values with unlike superscript letters were significantly different $(P<0.05)$. $\mathrm{AU}$, arbitrary units; D, effect of diet (butter $v$. linseed); $G$, effect of gender (females $v$. males); I, interaction between gender and diet effects; LDL-R, LDL receptor; SR-B1, scavenger receptor class B type 1.

interaction $(P<0.03)$ between gender and diet resulted, as in the liver, in a higher value in males fed the 'linseed oil' diet than in the other three groups.

\section{Hepatic lipoprotein receptors}

The amount of LDL receptors in the whole liver was $50 \%$ higher in females than in males, and $20 \%$ higher in animals fed the 'butter' diet than in those fed the 'linseed oil' one (Fig. 2). However, the effect of diet was significant in males only. In contrast to the LDL receptor, the amount of hepatic HDL receptors (SR-B1) was twice higher in males than in females and was not affected by the diet. Gender- and diet-related effects were the same when data were expressed per mg membrane protein (data not shown).

\section{Gene expression}

There were few effects of gender and diet on hepatic expression of transcription factors (Table 8). PPAR $\gamma$ expression was $40 \%$ lower in females than in males, whatever the diet. PPAR $\alpha$, liver $\mathrm{X}$ receptor $\alpha$ and SREBP2 expression was influenced neither by gender nor by diet. Hepatic mRNA level of SREBP1c was $46 \%$ higher, and that of oestrogen receptor was $46 \%$ lower in animals fed the 'linseed oil' diet than in those fed the 'butter' one.

\section{Discussion}

The present study was designed to compare, in male and female hamsters, the response of fatty acids and lipid metabolism to dietary fatty acids. It aimed to determine key factors of $\mathrm{CH}$ and $\mathrm{TG}$ metabolic pathways that are involved in the gender-related differences, as well as their impact on markers and risk factors of metabolic syndrome and CVD.

\section{Cholesterol metabolism}

The impact of gender was particularly obvious on $\mathrm{CH}$ metabolism, where it predominated over the influence of diet. Indeed, plasma $\mathrm{CH}$, LDL-CH and HDL-CH concentrations were higher in males than in females, whereas VLDL-CH concentration was lower (Fig. 1). This was associated with differences in lipoprotein receptors. Females exhibited more liver LDL receptors (Fig. 2), that could explain their weaker concentration of LDL-CH. As for HDL-CH and total HDL, however, their concentration was higher in males than in females despite a higher hepatic content of SR-B1. This may result from the low cholesteryl ester transfer protein activity found in male hamsters compared to females (Zuckerman \& Evans, 1995; Salter et al. 1998).

The influence of gender was also observed on hepatic $\mathrm{CH}$. The higher $\mathrm{CH}$ content of the liver from males could not be accounted for by differences in dietary $\mathrm{CH}$ absorption and hepatic $\mathrm{CH}$ synthesis, which were similar in both genders (Table 7). Alternately, it could result from (1) enhanced $\mathrm{CH}$ re-uptake due to elevated levels of both HDL-CH and SR-B1 (Figs 1(B) and 2) or (2) impaired hepatic CH secretion into VLDL, in accordance with the lower VLDL-CH concentration found in males (Fig. 1(B)).

In contrast to that of gender, the effect of diet on $\mathrm{CH}$ metabolism was slight and significant in males only: males fed the 'linseed oil' diet exhibited lower plasma concentration of HDL-CH, liver $\mathrm{CH}$ content and higher bile concentration of

Table 8. Effect of gender and diet on the expression of transcription factor and key genes of lipid metabolism (arbitrary units)* (Mean values with their standard errors for nine hamsters per group)

\begin{tabular}{|c|c|c|c|c|c|c|c|c|c|c|c|}
\hline & \multicolumn{4}{|c|}{ Females } & \multicolumn{4}{|c|}{ Males } & & & \\
\hline & \multicolumn{2}{|c|}{ 'Butter' } & \multicolumn{2}{|c|}{ 'Linseed oil' } & \multicolumn{2}{|c|}{ 'Butter' } & \multicolumn{2}{|c|}{ 'Linseed oil' } & \multicolumn{3}{|c|}{ Effects† } \\
\hline & Mean & SEM & Mean & SEM & Mean & SEM & Mean & SEM & $\mathrm{G}$ & $\mathrm{D}$ & I \\
\hline $\operatorname{PPAR} \alpha$ & $715^{\mathrm{b}}$ & 98 & $1106^{a}$ & 130 & $805^{a b}$ & 70 & $808^{\mathrm{ab}}$ & 113 & 0.324 & 0.066 & 0.071 \\
\hline PPAR $\gamma$ & $15 \cdot 0^{\mathrm{b}}$ & 3.5 & $21 \cdot 1^{\mathrm{b}}$ & $4 \cdot 2$ & $24 \cdot 9^{a b}$ & $4 \cdot 8$ & $37 \cdot 5^{a}$ & 6.7 & 0.012 & 0.067 & 0.514 \\
\hline SREBP1C & 153 & 31 & 242 & 43 & 148 & 26 & 199 & 32 & 0.489 & 0.050 & 0.580 \\
\hline Liver $\mathrm{X}$ receptor $\alpha$ & $217^{\mathrm{b}}$ & 45 & $318^{a b}$ & 28 & $302^{a b}$ & 34 & $340^{\mathrm{a}}$ & 54 & 0.218 & 0.111 & 0.464 \\
\hline Oestrogen receptor & $4.08^{a}$ & 0.87 & $2.98^{\mathrm{ab}}$ & 0.52 & $4 \cdot 68^{a}$ & 0.88 & $1.72^{b}$ & 0.31 & 0.646 & 0.007 & 0.201 \\
\hline
\end{tabular}

SREBP, sterol response element binding protein.

${ }^{*}$ For details of procedures and diets, see pp. 710-711 and Table 1.

$\dagger G, D$ and $I$ are the effects of gender, diet and interaction between both treatments after two-way ANOVA.

Mean values within a row with unlike superscript letters were significantly different $(P<0.05)$. 
CH than males fed the 'butter' diet (Table 6; Fig. 1(B)). Thus, the 'linseed oil' diet could decrease HDL-CH and liver $\mathrm{CH}$ by increasing $\mathrm{CH}$ excretion via the bile, but only in males.

\section{Triacylglycerol metabolism}

In contrast to $\mathrm{CH}$ metabolism, TG metabolism was affected by diet mostly. Indeed, plasma and liver TG concentrations were lower in animals fed the 'linseed oil' diet, which may result from a decreased lipogenesis or an increased fatty acid oxidation in the liver (Table 7). Indeed, two correlations could be established between the concentration of VLDL-TG, on the one hand, and total hepatic activity of ACC and FAS, on the other hand $\left(R^{2} 0.15, P=0.02\right.$ and $R^{2} 0.30, P<0.001$, respectively). However, we could not establish any correlation between triglyceridaemia and hepatic CPT activity. Despite an increased $\beta$-oxidation activity in animals fed the 'linseed oil' diet, PPAR $\alpha$ transcription, that is activated by PUFA (Kersten et al. 1999), was not increased in the present study with the ALA-rich diet (Table 8). Besides, $n-3$ long-chain PUFA (EPA and DHA) are known to decrease lipogenesis by decreasing SREBP1c mature protein amount and expression (Xu et al. 2002). On the contrary, in the present study, dietary ALA increased SREBP1c mRNA levels. It seems therefore that the mechanisms underlying the decrease in lipogenesis by dietary ALA, precursor of EPA and DHA, were different from those of its long-chain derivatives and may not involve SREBP1c. This also suggests that ALA may regulate some key points of lipid metabolism directly, without being converted into its long-chain derivatives. Moreover, decreased lipogenesis and increased $\beta$-oxidation in response to the 'linseed oil' diet were much pronounced in males than in females. This gender-specific sensitivity to diet did not seem to be due to hepatic levels of PPAR $\alpha$ and SREBP1c transcripts that were similar in both genders.

Oestrogens are also involved in the regulation of many key enzymes of TG metabolism through the oestrogen receptor. In particular, oestradiol treatment of ovariectomized rats decreased the expression (Gower et al. 2002) and the activity (Weinstein et al. 1986) of CPT, and increased the activity of FAS and ACC (Abraham et al. 1980). In the present study, the transcription of the oestrogen receptor was higher in hamsters fed the 'butter' diet (Table 8). Therefore, these animals could have a higher sensitivity to oestrogens that could contribute to their higher TG content in liver and plasma. On the contrary, whereas dietary fatty acids seemed to influence the transcription of the oestrogen receptor, gender did not affect mRNA levels of PPAR $\alpha$ and SREBP1c (Table 8). Therefore, the much more pronounced response to diet of males may not linked to the level of PPAR $\alpha$ and SREBP1c transcription.

\section{Other parameters involved in metabolic syndrome and CVD}

In erythrocytes from hamsters fed linseed oil, the total n-3 PUFA content was twice higher than in those from hamsters fed butter, whereas $n-6$ to $n-3$ and AA to EPA ratios were beneficially lowered (Table 3 ). This increase in $n-3$ bioavailability did not result in a higher susceptibility to peroxidation, since malondialdehyde content did not differ with the diet (Table 5).

Besides, among animals fed the 'linseed oil' diet, females had reduced LA to ALA and n-6 to $n$-3 PUFA ratios. However, the AA to EPA ratio did not vary with gender, suggesting that gender did not influence the balance of eicosanoids originating from these two PUFA. Such effect of gender on ALA conversion into its long-chain derivatives has been found in human studies, in which women exhibited a higher capacity of conversion than men (Burdge \& Wootton, 2002). The present results did not allow us to confirm this observation in the hamster. However, they highlight the impact of gender on fatty acid incorporation into tissues. Not only lipid metabolism, but also glucose homeostasis, which is involved in metabolic syndrome and CVD, was improved by the "linseed oil' diet. Indeed, glycaemia, insulinaemia and therefore the insulin resistance index (HOMA) were lower in animals fed the 'linseed oil' diet (Table 5). This confirms the improvement of insulin sensitivity by dietary ALA (Manco et al. 2004; Ghafoorunissa et al. 2005).

Besides, the decrease in glycaemia in response to the ALArich diet was much more pronounced in females, whereas that of insulinaemia was more pronounced in males (Table 5). Since PPAR $\gamma$ agonists like PUFA are insulin sensitizers (Saltiel \& Olefsky, 1996; Xu et al. 1999), the higher hepatic level of PPAR $\gamma$ transcripts in males could make their glucose control more sensitive to dietary fatty acids (Table 8 ).

\section{Conclusion}

The present study showed that male and female hamsters responded differently to dietary fatty acids. Moreover, gender and diet exerted differential effects on the metabolism of individual lipid classes. Indeed, $\mathrm{CH}$ metabolism was affected by gender mostly, whereas TG metabolism was more sensitive to dietary fatty acids, males being more responsive than females.

As a consequence, male hamsters, which exhibited higher lipid risk factors of CVD and metabolic syndrome than females, seemed to benefit more from an ALA-rich diet. The relevance of these observations has to be investigated in man, which raises the question of taking gender into account when establishing lipid dietary recommendations.

\section{Acknowledgements}

The authors gratefully acknowledge the financial support of ONIDOL and ONIOL. They also thank sincerely Guillaume Chesneau and the Valorex Company (La Messayais, Combourtillé, France) for providing linseed oil, Gwennola Robin (SENAH) for her valuable contribution to the measurement of lipogenic enzyme activities, as well as Jean-Charles Martin, Jacqueline Férézou and Colette Sérougne (Université Paris Sud, France) and François Mariotti (INA-PG, France) for their precious scientific advice.

\section{References}

Abraham S, Hillyard LA, Hansen FN \& Lin CY (1980) Tissue specificity for the effect of estrogen on lipogenic activity in male and female rats. Biochim Biophys Acta 620, 167-171.

Acton S, Rigotti A, Landschulz KT, Xu S, Hobbs HH \& Krieger M (1996) Identification of scavenger receptor SR-BI as a high density lipoprotein receptor. Science 271, 518-520.

Ascherio A, Rimm EB, Giovannucci EL, Spiegelman D, Stampfer M $\&$ Willett WC (1996) Dietary fat and risk of coronary heart disease 
in men: cohort follow up study in the United States. Br Med J 313, 84-90.

Bieber LL, Abraham T \& Helmrath T (1972) A rapid spectrophotometric assay for carnitine palmitoyltransferase. Anal Biochem 50, $509-518$.

Boehler N, Riottot M, Ferezou J, Souidi M, Milliat F, Serougne C, Smith JL \& Lutton C (1999) Antilithiasic effect of beta-cyclodextrin in LPN hamster: comparison with cholestyramine. J Lipid Res 40, 726-734.

Bonithon-Kopp C, Scarabin PY, Darne B, Malmejac A \& Guize L (1990) Menopause-related changes in lipoproteins and some other cardiovascular risk factors. Int J Epidemiol 19, 42-48.

Boué C, Combe N, Billeaud C, Mignerot C, Entressangles B, Thery G, Geoffrion H, Brun JL, Dallay D \& Leng JJ (2000) Trans fatty acids in adipose tissue of French women in relation to their dietary sources. Lipids 35, 561-566.

Burdge GC \& Wootton SA (2002) Conversion of alpha-linolenic acid to eicosapentaenoic, docosapentaenoic and docosahexaenoic acids in young women. Br J Nutr 88, 411-420.

Carlson LA \& Ericsson M (1975) Quantitative and qualitative serum lipoprotein analysis. Part 1. Studies in healthy men and women. Atherosclerosis 21, 417-433.

Chakrabarty K \& Leveille GA (1969) Acetyl CoA carboxylase and fatty acid synthetase activities in liver and adipose tissue of meal-fed rats. Proc Soc Exp Biol Med 131, 1051-1054.

Chang HC, Seidman I, Teebor G \& Lane MD (1967) Liver acetyl CoA carboxylase and fatty acid synthetase: relative activities in the normal state and in hereditary obesity. Biochem Biophys Res Commun 28, 682-686.

Chomczynski P, Qasba P \& Topper YJ (1986) Transcriptional and post-transcriptional roles of glucocorticoid in the expression of the rat 25,000 molecular weight casein gene. Biochem Biophys Res Commun 134, 812-818.

Cobb M, Greenspan J, Timmons M \& Teitelbaum H (1993) Gender differences in lipoprotein responses to diet. Ann Nutr Metab 37, $225-236$.

Couillard C, Bergeron N, Prud'homme D, Bergeron J, Tremblay A, Bouchard C, Mauriege P \& Despres JP (1999) Gender difference in postprandial lipemia: importance of visceral adipose tissue accumulation. Arterioscler Thromb Vasc Biol 19, 2448-2455.

De Caterina R \& Zampolli A (2001) n-3 Fatty acids: antiatherosclerotic effects. Lipids 36, S69-S78.

Djousse L, Hunt SC, Arnett DK, Province MA, Eckfeldt JH \& Ellison RC (2003) Dietary linolenic acid is inversely associated with plasma triacylglycerol: the National Heart, Lung, and Blood Institute Family Heart Study. Am J Clin Nutr 78, 1098-1102.

Ferezou J, Riottot M, Serougne C, et al. (1997) Hypocholesterolemic action of beta-cyclodextrin and its effects on cholesterol metabolism in pigs fed a cholesterol-enriched diet. J Lipid Res 38, 86-100.

Fernandez ML (2001) Dietary fat saturation and gender/hormonal status modulate plasma lipids and lipoprotein composition. J Nutr Biochem 12, 703-710.

Fitch WM, Hill R \& Chaikoff IL (1959) The effect of fructose feeding on glycolytic enzyme activities of the normal rat liver. $J$ Biol Chem 234, 1048-1051.

Folch J, Lees M \& Sloane-Stanley GH (1957) A simple method for the isolation and purification of total lipids from animal tissues. J Biol Biochem 226, 497-509.

Fossati P \& Prencipe L (1982) Serum triglycerides determined colorimetrically with an enzyme that produces hydrogen peroxide. Clin Chem 28, 2077-2080.

Gandemer G, Pascal G \& Durand G (1983) Lipogenic capacity and relative contribution of the different tissues and organs to lipid synthesis in male rat. Reprod Nutr Dev 23, 575-586.

Ghafoorunissa, Ibrahim A \& Natarajan S (2005) Substituting dietary linoleic acid with alpha-linolenic acid improves insulin sensitivity in sucrose fed rats. Biochim Biophys Acta 1733, 67-75.
Goulinet S \& Chapman MJ (1993) Plasma lipoproteins in the golden Syrian hamster (Mesocricetus auratus): heterogeneity of apoB- and apoA-I-containing particles. J Lipid Res 34, 943-959.

Gower BA, Nagy TR, Blaylock ML, Wang C \& Nyman L (2002) Estradiol may limit lipid oxidation via $\mathrm{Cpt} 1$ expression and hormonal mechanisms. Obes Res 10, 167-172.

Hsu RY \& Lardy HA (1969) Malic enzyme. In Methods in Enzymology, vol. 13, pp. 230-235 [JM Lowenstein, editor]. New York: Academic Press.

Hu FB, Stampfer MJ, Manson JE, Rimm E, Colditz GA, Rosner BA, Hennekens CH \& Willett WC (1997) Dietary fat intake and the risk of coronary heart disease in women. $N$ Engl J Med 337, $1491-1499$.

Kersten S, Seydoux J, Peters JM, Gonzalez FJ, Desvergne B \& Wahli W (1999) Peroxisome proliferator-activated receptor alpha mediates the adaptive response to fasting. J Clin Invest 103, 1489-1498.

Lapenna D, Ciofani G, Pierdomenico SD, Giamberardino MA \& Cuccurullo F (2001) Reaction conditions affecting the relationship between thiobarbituric acid reactivity and lipid peroxides in human plasma. Free Radic Biol Med 31, 331-335.

Lavau M, Bazin R, Karaoghlanian Z \& Guichard C (1982) Evidence for a high fatty acid synthesis activity in interscapular brown adipose tissue of genetically obese Zucker rats. Biochem J 204, 503-507.

Lazarow PB \& De Duve C (1976) A fatty acyl-CoA oxidizing system in rat liver peroxisomes; enhancement by clofibrate, a hypolipidemic drug. Proc Natl Acad Sci USA 73, 2043-2046.

Li Z, Otvos JD, Lamon-Fava S, Carrasco WV, Lichtenstein AH, McNamara JR, Ordovas JM \& Schaefer EJ (2003) Men and women differ in lipoprotein response to dietary saturated fat and cholesterol restriction. J Nutr 133, 3428-3433.

Lloyd-Jones DM, Larson MG, Beiser A \& Levy D (1999) Lifetime risk of developing coronary heart disease. Lancet 353, 89-92.

Loison C, Mendy F, Serougne C \& Lutton C (2002) Dietary myristic acid modifies the HDL-cholesterol concentration and liver scavenger receptor BI expression in the hamster. Br J Nutr 87, 199-210.

Lowry OH, Rosebrough NJ, Farr AL \& Randal RJ (1951) Protein measurement with the Folin phenol reagent. J Biol Chem 193, $265-275$.

Manco M, Calvani M \& Mingrone G (2004) Effects of dietary fatty acids on insulin sensitivity and secretion. Diabetes Obes Metab 6, 402-413.

Matthews DR, Hosker JP, Rudenski AS, Naylor BA, Treacher DF \& Turner RC (1985) Homeostasis model assessment: insulin resistance and beta-cell function from fasting plasma glucose and insulin concentrations in man. Diabetologia 28, 412-419.

Matthews KA, Meilahn E, Kuller LH, Kelsey SF, Caggiula AW \& Wing RR (1989) Menopause and risk factors for coronary heart disease. $N$ Engl J Med 321, 641-646.

Menke T, Niklowitz P, Adam S, Weber M, Schluter B \& Andler W (2000) Simultaneous detection of ubiquinol-10, ubiquinone-10, and tocopherols in human plasma microsamples and macrosamples as a marker of oxidative damage in neonates and infants. Anal Biochem 282, 209-217.

Milliat F, Gripois D, Blouquit ME, Ferezou J, Serougne C, Fidge NH \& Lutton C (2000) Short and long-term effects of streptozotocin on dietary cholesterol absorption, plasma lipoproteins and liver lipoprotein receptors in RICO rats. Exp Clin Endocrinol Diabetes 108, 436-446.

Morise A, Combe N, Boué C, Legrand P, Catheline D, Delplanque B, Fénart E, Weill P \& Hermier D (2004a) Dose effect of alpha-linolenic acid on PUFA conversion, bioavailability and storage in the hamster. Lipids 39, 325-334.

Morise A, Mourot J, Riottot M, Weill P, Fenart E \& Hermier D (2005) Dose effect of alpha-linolenic acid on lipid metabolism in the hamster. Reprod Nutr Dev 45, 405-418. 
Morise A, Sérougne C, Gripois D, Blouquit MF, Lutton C \& Hermier D (2004b) Effects of dietary alpha linolenic acid on cholesterol metabolism in male and female hamsters of the LPN strain. J Nutr Biochem 15, 51-61.

Morisson W \& Smith L (1964) Preparation of fatty acid methyl esters and dimetylacetals from lipids with boron fluoride methanol. J Lipid Res 5, 600-608.

Mourot J, Guy G, Lagarrigue S, Peiniau P \& Hermier D (2000) Role of hepatic lipogenesis in the susceptibility to fatty liver in the goose (Anser anser). Comp Biochem Physiol B Biochem Mol Biol 126, 81-87.

Noonan WT \& Banks RO (2000) Renal function and glucose transport in male and female mice with diet-induced type II diabetes mellitus. Proc Soc Exp Biol Med 225, 221-230.

Pawlosky RJ, Hibbeln JR, Novotny JA \& Salem N Jr (2001) Physiological compartmental analysis of alpha-linolenic acid metabolism in adult humans. J Lipid Res 42, 1257-1265.

Philipp BW \& Shapiro DJ (1979) Improved methods for the assay and activation of 3-hydroxy-3-methylglutaryl coenzyme A reductase. J Lipid Res 20, 588-593.

Quintao E, Grundy SM \& Ahrens EH Jr (1971) An evaluation of four methods for measuring cholesterol absorption by the intestine in man. J Lipid Res 12, 221-232.

Richmond W (1973) Preparation and properties of a cholesterol oxidase from Nocardia sp. and its application to the enzymatic assay of total cholesterol in serum. Clin Chem 19, 1350-1356.

Salter AM, Mangiapane EH, Bennett AJ, Bruce JS, Billett MA, Anderton KL, Marenah CB, Lawson N \& White DA (1998) The effect of different dietary fatty acids on lipoprotein metabolism: concentration-dependent effects of diets enriched in oleic, myristic, palmitic and stearic acids. Br J Nutr 79, 195-202.

Saltiel AR \& Olefsky JM (1996) Thiazolidinediones in the treatment of insulin resistance and type II diabetes. Diabetes 45, 1661-1669.

Souidi M, Parquet M, Ferezou J \& Lutton C (1999) Modulation of cholesterol 7alpha-hydroxylase and sterol 27-hydroxylase activities by steroids and physiological conditions in hamster. Life Sci 64, $1585-1593$.

Spady DK, Kearney DM \& Hobbs HH (1999) Polyunsaturated fatty acids up-regulate hepatic scavenger receptor B1 (SR-BI) expression and HDL cholesteryl ester uptake in the hamster. J Lipid Res 40, 1384-1394.

Stampfer MJ, Colditz GA, Willett WC, Manson JE, Rosner B, Speizer FE \& Hennekens CH (1991) Postmenopausal estrogen therapy and cardiovascular disease. Ten-year follow-up from the nurses' health study. $N$ Engl J Med 325, 756-762.

Surette ME, Whelan J, Lu GP, Broughton KS \& Kinsella JE (1992) Dependence on dietary cholesterol for n-3 polyunsaturated fatty acid-induced changes in plasma cholesterol in the Syrian hamster. J Lipid Res 33, 263-271.

Takada R, Saitoh M \& Mori T (1994) Dietary gamma-linolenic acidenriched oil reduces body fat content and induces liver enzyme activities relating to fatty acid beta-oxidation in rats. J Nutr 124, 469-474.

Takayama M, Itoh S, Nagasaki T \& Tanimizu I (1977) A new enzymatic method for determination of serum choline-containing phospholipids. Clin Chim Acta 79, 93-98.

Trinder P (1969) Determination of glucose in blood using glucose oxidase with an alternative oxygen acceptor. Ann Clin Biochem 6, 24-27.

Turley SD \& Dietschy JM (1978) Re-evaluation of the 3 alphahydroxysteroid dehydrogenase assay for total bile acids in bile. J Lipid Res 19, 924-928.

van Beek AP, de Ruijter-Heijstek FC, Erkelens DW \& de Bruin TW (1999) Menopause is associated with reduced protection from postprandial lipemia. Arterioscler Thromb Vasc Biol 19, 2737-2741.

Weinstein I, Cook GA \& Heimberg M (1986) Regulation by oestrogen of carnitine palmitoyltransferase in hepatic mitochondria. Biochem J 237, 593-596.

Wilkinson P, Leach C, Ah-Sing EE, Hussain N, Miller GJ, Millward DJ $\&$ Griffin BA (2005) Influence of alpha-linolenic acid and fish-oil on markers of cardiovascular risk in subjects with an atherogenic lipoprotein phenotype. Atherosclerosis 181, 115-124.

Wilson TA, Nicolosi RJ, Lawton CW \& Babiak J (1999) Gender differences in response to a hypercholesterolemic diet in hamsters: effects on plasma lipoprotein cholesterol concentrations and early aortic atherosclerosis. Atherosclerosis 146, 83-91.

Xu HE, Lambert MH, Montana VG, et al. (1999) Molecular recognition of fatty acids by peroxisome proliferator-activated receptors. Mol Cell 3, 397-403.

Xu J, Cho H, O’Malley S, Park JH \& Clarke SD (2002) Dietary polyunsaturated fats regulate rat liver sterol regulatory element binding proteins-1 and -2 in three distinct stages and by different mechanisms. J Nutr 132, 3333-3339.

Zuckerman SH \& Evans GF (1995) Cholesteryl ester transfer protein inhibition in hypercholesterolemic hamsters: kinetics of apoprotein changes. Lipids 30, 307-311. 